\title{
Obesidade Infantil e Abordagens em Psicologia: Uma Revisão da Literatura
}

\author{
Raimunda Alice dos Santos ${ }^{1}$; Thércia Lucena Grangeiro Maranhão ${ }^{2}$; Hermes Melo Teixeira Batista ${ }^{3}$
}

\begin{abstract}
Resumo: A obesidade atualmente é um grave problema de saúde pública em diversos países, atingindo o nível de pandemia. As consequências da obesidade, e em específico da obesidade infantil, transcendem o comprometimento da saúde meramente física, criando desta forma consequências sociais, psicossociais e na psicodinâmica subjetiva. $\mathrm{O}$ atual tratamento da obesidade é multidisciplinar, considerando aspectos orgânicos, ambientais, socioculturais e psicológicos. Diversos estudos relacionam obesidade e outras doenças orgânicas, assim como uma menor expectativa de vida para pessoas obesas. Da perspectiva da psicologia, diversos problemas emocionais, comportamentais e de socialização estão associados a indivíduos obesos. O aumento constante da população infantil obesa é amplo fator de risco à saúde, podendo interferir de forma danosa no processo de desenvolvimento normal. O presente trabalho monográfico busca através da revisão bibliográfica analisar e problematizar a inserção do psicólogo no tratamento da obesidade infantil, discutindo a etiologia e epidemiologia da obesidade no Brasil, apresentando os principais modelos teóricos, o impacto no desenvolvimento normal do individuo e os modelos de intervenção tanto clínicos como psicossociais e de prevenção e promoção da saúde.
\end{abstract}

Palavras-chave: Obesidade. Obesidade infantil. Saúde pública. Psicologia. Psicologia clinica. Psicossociologia.

\section{Childhood Obesity and Approaches in Psychology: A Review of Literature}

\begin{abstract}
Obesity is currently a major public health problem in many countries, reaching a pandemic level. The consequences of obesity, and in particular childhood obesity, impaired transcend the merely physical health, thus creating social, psychosocial and psychodynamic subjective consequences. Current treatment of obesity is multidisciplinary, considering organic, environmental, sociocultural and psychological aspects. Several studies have linked obesity and other organic diseases, as well as a lower life expectancy for obese people. From the perspective of psychology, various emotional, behavioral and socialization problems are associated with obese individuals. The steady increase in obese pediatric population is larger risk factor to health and can interfere with the harmful way in the normal development process. This monograph search through the literature review to analyze and discuss the inclusion of psychologists in the treatment of childhood obesity, discussing the etiology and epidemiology of obesity in Brazil, presenting the main theoretical models, the impact on the normal development of the individual and intervention models both clinical and psychosocial and prevention and health promotion.
\end{abstract}

Keywords: Obesity. Childhood obesity. Public health. Psychology. Clinical Psychology. Psychosociology. Health education.

\footnotetext{
${ }^{1}$ Graduanda em Psicologia pela Universidade Doutor Leão Sampaio - UNILEÃO;

${ }^{2}$ Graduada em Psicologia pela Faculdade de Ciências Humanas - ESUDA (2004). Especialista em Formação de Professores para o Ensino Superior, pela Faculdade de Juazeiro do Norte . Especialista em Gestão do Trabalho e da Educação na Saúde, pela Escola de Saúde Pública do Ceará . Atualmente é professora da Faculdade Leão Sampaio. E-mail: therciapsicologa@gmail.com;

${ }^{3}$ Médico pela Universidade Federal do Ceará. Médico do Hopital do cariri. Professor da Faculdade de Medicina de Juazeiro do Norte - FMJ. E-mail: hermesmelo@oi.com.br;
} 


\section{Introdução}

A obesidade é um problema que afeta várias sociedades e está relacionada ao excesso de gordura em relação à massa magra que compõe o corpo do indivíduo. Ela afeta cerca de 42 milhões de crianças (até 2010) em todo mundo e é considerada pela Organização Mundial de Saúde - OMS - um dos problemas mais graves do século XXI.

Entende-se que a obesidade se tornou uma epidemia. Depois do tabaco, ela é a principal causa de morbilidade e mortalidade nos Estado Unidos da América (cerca de 300.000 mortes lhe são atribuídas). Crianças obesas tendem a se tornar, posteriormente, jovens e adultos obesos, além do mais, quanto mais precoce ela for afetada por este distúrbio, mais suscetível ela está de se tornar um adulto com sobrepeso.

$\mathrm{O}$ risco de aparecimento de doenças (de vários graus e tipos) nos portadores desse tipo de distúrbio é bem mais elevado quando comparado com pessoas que possuem índice de massa corporal compatível com a estatura. Não obstante, crianças obesas tendem a desenvolver problemas psicológicos, pois as mesmas, muitas vezes, acabam sendo isoladas pelos grupos sociais de seu convívio, sua autoestima é baixa, elas são menos incluídas em atividades físicas (já que são considerados lentos, menos hábeis, dentre outros estereótipos). Alguns autores acreditam que a discriminação social sofrida pelos obesos faz com eles passem a não gostar de si mesmos (esse desagrado já é observado em crianças da pré-escola).

Segundo a OMS, apesar de ser um problema muito antigo, o sobrepeso tornou-se epidêmico há pouco tempo. Observa-se que as mudanças globais influenciaram para que isso acontecesse. A tecnologia é uma das principais vilãs nesta história. O desenvolvimento dos computadores, tablets, aparelhos de televisão, vídeo-games, dentre outros aparelhos eletrônicos, contribuem para o sedentarismo. Os alimentos industrializados também influenciam de forma marcante no balanço energético.

Pretende-se neste trabalho destacar a contribuição e a importância do psicólogo no tratamento da obesidade infantil. É sabido que a obesidade não é um distúrbio meramente psicológico, entretanto esse profissional apresenta um certo potencial na intervenção e tratamento do sobrepeso. Partiu-se da ideia que o interesse pelo tema surge com o estudo relacionado ao desenvolvimento infantil e obesidade, tornando-se um tema prazeroso que motivou a busca por outras informações. A partir deste interesse surge a pergunta: Qual o papel do psicólogo no tratamento da obesidade? O mesmo irá trabalhar os sintomas e queixas de seus pacientes, ouvi-lo é o primeiro passo para que haja a identificação dos causadores e dos mantenedores do sobrepeso. Com isso, a autoestima, a imagem corporal que a criança tem de si, a depressão (que muitas vezes é desenvolvida pelo fato de a criança 
ser excluída dos grupos sociais), os distúrbios alimentares que podem surgir, e vários outros problemas serão trabalhados e recuperados através do tratamento psicológico.

Vê-se como objetivo geral, neste trabalho, destacar a importância do psicólogo para o tratamento da obesidade e até mesmo uma futura diminuição nas taxas de prevalência desse distúrbio. Como, também, identificar quais os fatores de risco da obesidade infantil; observar a relação entre hábitos alimentares e obesidade; observar a relação entre o psicólogo e o paciente para que o desenvolvimento saudável seja garantido.

\section{Metodologia}

A metodologia traça os procedimentos, ferramentas e caminhos que serão utilizados para realizar as pesquisas.

Ainda sobre a definição de metodologia, de acordo com Silva e Menezes (2001) a metodologia destina-se a mostrar os caminhos a percorrer durante a pesquisa, ajudar a refletir e instigar um novo olhar sobre a realidade: um olhar curioso, criterioso, inovador, interpretativo e criativo.

[...] a elaboração de um projeto de pesquisa e o desenvolvimento da própria pesquisa, seja ela uma dissertação ou tese, necessitam, para que seus resultados sejam satisfatórios, estarem baseados em planejamento cuidadoso, reflexões conceituais [...] (SILVA; MENEZES, 2001, p.09).

É uma pesquisa bibliográfica no sentido de aprofundar o conhecimento sobre o assunto buscando ideias iniciais da unificação de alguns artigos e autores que discutam o assunto mostrando as causas da ocorrência da obesidade infantil. O método empregado busca descrever a temática fazendo um estudo retrospectivo, de caráter qualitativo.

A pesquisa bibliográfica será destinada a colocar em discussão a contribuição e a importância do psicólogo no tratamento da obesidade infantil, pois sabe-se que o mesmo apresenta um grande potencial na intervenção e no tratamento do sobrepeso. Além de apresentar fatos que comprovem a eficiência dessa intervenção psicológica no tratamento da obesidade infantil.

\section{Obesidade Infantil: Caracterização e Epidemiologia}

A obesidade é atualmente entendida epidemiologicamente como uma doença crônica não transmissível de causalidade multifatorial, e concomitantemente é fator de riscos para outras doenças crônicas não transmissíveis tais como hipertensão arterial e diabetes (BRASIL, 2006). A obesidade é 
definida pela Organização Mundial da Saúde (OMS) como o grau de armazenamento de gordura no organismo associado a riscos para a saúde, devido à relação com várias complicações metabólicas (ORGANIZAÇÃO MUNDIAL DA SAÚDE, 2004). A obesidade é definida na prática como excesso de peso aferido em situações clínicas pelo Índice de Massa Corporal (IMC).

A obesidade integra o grupo de Doenças e Agravos Não Transmissíveis (DANTs). As DANTs podem ser caracterizadas por doenças com história natural prolongada, múltiplos fatores de risco, interação de fatores etiológicos, especificidade de causa desconhecida, ausência de participação ou participação polêmica de microorganismos entre os determinantes, longo período de latência, longo curso assintomático, curso clínico em geral lento, prolongado e permanente, manifestações clinicas com períodos de remissão e de exacerbação, lesões celulares irreversíveis e evolução para diferentes graus de incapacidade ou para a morte (BRASIL, 2006, p. 22)

A magnitude e a velocidade da evolução da obesidade em vários países do mundo, tanto desenvolvidos como em desenvolvimento, incluso o Brasil, contribuem para sua categorização como uma pandemia. Dados recentes revelam que cerca de $12,7 \%$ das mulheres e $8,8 \%$ dos homens adultos brasileiros são obesos, atingindo todas as faixas de renda e com prevalência geográfica nas regiões Sul e Sudeste do país (INSTITUTO BRASILEIRO DE GEOGRAFIA E ESTATÍSTICA, 2004).

Entre crianças e adolescentes brasileiros houve um grande aumento do excesso de peso entre as décadas de 70 e 90 do século XX. Em 1974 a prevalência de excesso de peso entre crianças entre 6 e 9 anos era de 4,9\%, e entre adolescentes de 10 a 18 anos era de 3,7\%. Em 1997 observou-se no Brasil uma taxa de 14\% de excesso de peso na faixa etária entre 6 e 18 anos (WANG et al., 2002). Numa perspectiva mundial, atualmente estima-se que cerca de $25 \%$ das crianças americanas sejam obesas. Relatos da OMS afirmam que a obesidade infantil tem crescido em torno de 10 a $40 \%$ na maioria dos países europeus nos últimos dez anos.

As consequências da obesidade no geral, e da obesidade infantil em específico transcendem o comprometimento da saúde meramente física, criando desta forma consequências sociais, psicossociais e na psicodinâmica subjetiva.

Todas essas consequências possuem relação direta com a etiologia multifatorial da obesidade e também implicam em múltiplas e diversas formas de tratamento e cuidado.

\section{Etiologia Multifatorial da Obesidade}

Falar em etiologia multifatorial da obesidade significa considerar como causalidade variáveis biológicas, genéticas, ambientais, sociais, econômicas, culturais e por fim psicológicas, em múltiplos 
enfoques que perpassam desde o comportamentalismo até a chamada psicologia dinâmica ou profunda.

Há uma categorização clássica da etiologia da obesidade em:

- Obesidade Endógena: envolve fatores causais internos. Neuroendócrinos, genéticos, fisiológicos, metabólicos. Onde também caberia além do viés biológico a perspectiva da psicologia dinâmica, em específico a psicanálise e o funcionamento do aparelho psíquico;

- Obesidade Exógena: envolve fatores causais externos. Ambientais, sociais, culturais, econômicos e, do ponto de vista psicológico, psicossociais e comportamentais.

Quanto aos fatores endógenos biológicos, estudos indicam que apenas 5\% dos casos de obesidade infantil se enquadram nessa definição, com primazia para o fator genético que se manifesta como uma predisposição metabólica para ganhar peso. A herança genética numa família com histórico de obesidade é estimada em 50 a $80 \%$ de probabilidade de que os filhos venham a ser obesos em alguma etapa da vida (ORERA, 1997).

Várias são as consequências orgânicas da obesidade infantil. O ganho de peso inicial nas crianças é acompanhado por aumento de estatura e aceleração da idade óssea, porém com o ganho contínuo de peso a estatura e a idade óssea se mantêm constantes, favorecendo o surgimento de problemas nas articulações. Também em decorrência desse ganho contínuo de peso, a puberdade pode ser antecipada levando a uma altura final diminuída na criança causada pelo fechamento precoce das cartilagens de crescimento (MEYER; MELLO; LUFT, 2004).

A quantidade total de gordura está associada à ocorrência de doenças crônico-degenerativas. $\mathrm{O}$ sobrepeso triplica o risco de desenvolvimento de diabetes melito, outras complicações endócrinometabólicas possíveis são hipertrigliceridemia e hipercolesterolemia. A obesidade também é fator de risco independente para doenças coronarianas, hipertensão arterial sistêmica e hipertrofia cardíaca. Também a aterosclerose pode ter início na infância com depósito de colesterol nas artérias musculares. Complicações articulares decorrentes da obesidade incluem ainda artroses e osteoartrite. Complicações respiratórias associadas incluem asma, hipóxia, apnéia do sono e diminuição da eficiência muscular. Pacientes obesos possuem maior risco cirúrgico. Por último a obesidade, já na infância, possui correlação com uma maior taxa de mortalidade (MEYER; MELLO; LUFT, 2004).

Ainda relacionado a fatores internos da obesidade, ainda que não sejam fatores biologicistas, a abordagem psicodinâmica da obesidade tem buscado compreender as motivações inconscientes e a dinâmica psíquica interna de indivíduos obesos. Desta forma, fatores psicológicos internos relacionados à etiologia da obesidade estão associados a sofrimento psíquico que trazem danos à saúde mental do indivíduo obeso, podendo comorbidades psicológicas como quadros de depressão e ansiedade generalizada se instalarem. Variada e diversa também são as consequências psíquicas dessa psicodinâmica. Sentimentos de desprezo e inferioridade para consigo são comuns em crianças com 
sobrepeso. Características de personalidade tais como dependência, passividade, imaturidade e baixa autoestima possuem alta correlação com a obesidade infantil, o que se articula com a dinâmica psicossocial da criança, podendo acarretar tristeza e solidão. Dificuldades no convívio social são frequentemente relatadas (MISHIMA; BARBIERI, 2009).

Quanto aos fatores externos da obesidade, eles são prevalentes entre crianças e adolescentes. Fatores ambientais, marketing e cultura do consumo, além de hábitos e comportamentos nocivos à saúde são o principal motivador da busca por ajuda médico/clínica na obesidade infantil. O número de crianças e adolescentes obesos é alto tanto nas classes mais abastadas quanto nas mais pobres, com crescimento constante nessas últimas. O consumo de alimentos mais baratos, bastante calóricos e ricos em sais e gorduras transgênicas explica em parte esse crescimento (ORERA, 1997). Relacionados aos fatores externos da obesidade podemos destacar:

- Prolongada exposição à escassez de alimentos, intra ou extra-uterina, levando à desnutrição que contribui para uma futura tendência à obesidade;

- Substituição frequente e em larga escala de alimentos naturais por alimentos industrializados, como exemplo o desmame precoce e o uso de leite industrializado;

- Hábitos urbanos que favoreçam o sedentarismo;

- Cultura de consumo e marketing da indústria alimentícia;

- A própria percepção da imagem corporal, com identificação cultural de gordura com "saúde". Esses e outros fatores exógenos interagem entre si para propiciar um contexto favorável à obesidade.

Partindo dessa etiologia multicausal que engloba tanto fatores nutricionais, quanto socioeconômicos, biológicos e genéticos e a assimilação desses todos pela subjetivação da criança obesa, com destaques para a dinâmica psíquica inconsciente motivadora e para a eliciação de comportamentos indesejáveis, claro fica que a resposta para o adequado tratamento da obesidade, em específico da obesidade infantil, passa por diversas abordagens, sejam estas clínicas ou educativas.

Os capítulos seguintes em consonância com as discussões epidemiológicas e etiológicas tratarão da psicogênese da obesidade sobre variadas abordagens psicológicas; do enfoque em psicologia do desenvolvimento da obesidade; da psicossociologia da obesidade e seus componentes culturais e nutricionais; e das possibilidades de intervenção, sejam estas no âmbito da Educação em Saúde e Prevenção e Promoção da Saúde, ou no âmbito clínico. 


\section{Abordagens Psicológicas e Psicogênese da Obesidade Infantil}

Diversas são as abordagens possíveis da psicologia para com a obesidade. Grosso modo podemos fazer uma divisão entre às análises psicossociológicas do problema e às intervenções clínicas. Este capítulo busca apresentar dois modelos teóricos hegemônicos na prática clínica e no manejo da obesidade, em específico da obesidade infantil.

Psicogênese refere-se à causação psíquica de algo e articula-se com um modelo teórico que a sustente. Já foi discutido o atual entendimento do caráter multicausal da obesidade, nesta perspectiva de causação multifatorial a psicogênese não é algo isolado e determinístico, mas para o fazer psicológico é fundamental e determinante, sendo a porta de acesso para a intervenção clínica na obesidade no geral, e na obesidade infantil especificamente.

A seguir dois modelos teóricos opostos e excludentes serão apresentados. Ainda que diversos no entendimento e no manejo, esses modelos são os mais usados e mais eficazes na intervenção clínica psicológica da obesidade.

\section{Modelo Psicanalítico}

A Psicanálise Freudiana e suas derivações estão no grupo das chamadas psicologias profundas, são modelos teóricos que possuem uma visão clara do funcionamento psíquico interno do indivíduo e suas motivações. Aqui entra a noção de psicodinâmica do aparelho psíquico. Por considerar a existência da mente, a psicanálise também está dentro do grupo de teorias psicológicas mentalistas.

Todo o modelo psicanalítico é fundado a partir da noção de inconsciente. O sujeito da psicanálise é um sujeito clivado, dividido, e sua parte consciente perceptível é submetida e determinada por motivações inconscientes. Sendo o inconsciente uma parte da mente, ou do aparelho psíquico em termos freudianos, não acessível diretamente. Diversos foram o entendimento do inconsciente tanto no freudismo clássico quanto nas derivações subsequentes como por exemplo o lacanismo, mas em todos é central a noção de determinação inconsciente sobre o "eu" consciente e a necessidade no manejo clínico de revelar significados simbólicos profundos e o subjacente dinamismo psíquico. Sintomas e doenças se estruturam numa narrativa de significado inconsciente, com simbologia velada que necessita ser compreendida na clínica psicanalítica. Assim, a primazia do orgânico cede lugar às significações inconscientes, o ato de alimentar-se deixa de ser um ato orgânico, biológico, e passa a ter um significado único em cada narrativa inconsciente do indivíduo, e são essas significações inconscientes do alimento e do ato de comer, bem como a significação inconsciente do 
corpo do indivíduo, que estão na psicogênese da obesidade num viés psicanalítico. A fome nesse viés nunca é apenas de alimento, e a saciedade nunca é apenas biológica. "O simbólico, o onírico, os significantes, os mitos, os fantasmas e a sexualidade também compõem nossas refeições" (JUSTUS, 1999)

Sendo o inconsciente o conceito núcleo fundante da psicanálise, diversos outros se articulam e orbitam esse núcleo. Faz-se necessário uma concisa apresentação dos conceitos psicanalíticos relacionados ao entendimento da obesidade como psicopatologia, desta forma eles serão introduzidos a seguir:

\section{a) Sintoma:}

O sintoma é um conceito fundamental em psicanálise, e seu entendimento é algo bastante específico dentro da teoria psicanalítica, divergindo completamente da noção médica de sintoma, por exemplo.

Há uma trajetória do conceito de sintoma dentro da obra freudiana e suas derivações, inicialmente o sintoma é entendido como expressão de um conflito psíquico, evoluindo depois para uma mensagem do inconsciente e culminando como satisfação pulsional, naquilo que Lacan vai chamar de mensagem-metáfora.

Quinet (1991) coloca o sintoma na origem da psicanálise, é o sintoma entendido por Freud inicialmente como expressão de um conflito psíquico que estabelece a escuta analítica de ouvir um sentido onde antes não havia o que ser ouvido. Buscando entender o sintoma, Freud estava ouvindo o sujeito em sua radical singularidade.

Como dito, inicialmente o sintoma em psicanálise era o produto de um conflito inconsciente, uma espécie de cicatriz de um evento traumático inconsciente que esconde um significado também inconsciente.

Nas Conferências Introdutórias sobre Psicanálise, Freud diz que

(...) um sintoma é um produto consideravelmente deformado da satisfação inconsciente de um desejo libidinal, um produto equívoco, habilmente escolhido e possuindo duas significações diametralmente opostas. (FREUD, 1916, p. 141).

O sintoma é ao mesmo tempo uma mensagem cifrada, um alerta de um conflito psíquico inconsciente e também a própria expressão desse conflito, uma forma desse conflito chegar à consciência. Uma expressão disfarçada, deformada para não ser reconhecida. O sintoma se forma quando

(...) as duas forças que entraram em luta encontram-se novamente no sintoma e se reconciliam, por assim dizer, através do acordo representado pelo sintoma formado. 
É por essa razão, também, que o sintoma é tão resistente: é apoiado por ambas as partes em luta. (FREUD, 1917, p. 361).

O sintoma atende dois senhores, a repressão do conteúdo inconsciente intolerável e a própria expressão desse conteúdo.

A prática clínica psicanalítica confirma a dificuldade no manejo do sintoma, pois ele é também a expressão de uma satisfação. Apenas num trabalho clínico de ressignificação do sintoma o paciente vai aos poucos cedendo em sua resistência.

Contudo, a prática clínica do Freud o levou de encontro a pacientes que simplesmente não conseguiam abrir mão de seus sintomas, o que culminou a partir de 1920 numa nova concepção do aparelho psíquico e das forças que organizam o seu funcionamento. Desta forma, a partir de 1920 quando foi publicado "Além do princípio do prazer" o sintoma passa a ter duas faces: o sintoma como efeito lacunar, como uma mensagem passível de interpretação analítica; e o sintoma como satisfação pulsional, que é a face do sintoma que resiste ao tratamento analítico. Em termos lacanianos, o indivíduo goza em seu sintoma, e por esse motivo é tão difícil para o paciente abrir mão dele.

O sintoma é

(...) o verdadeiro substitutivo e derivativo do impulso inconsciente reprimido (...) continuamente renova suas exigências de satisfação e assim, obriga o ego, por sua vez a dar o sinal de desprazer e a colocar-se em uma posição de defesa. (FREUD, 1926, p. 103)

Surge assim a concepção amplamente conhecida em psicanálise do sintoma como uma solução de compromisso entre consciente e inconsciente. O sintoma é uma resposta a uma satisfação insuportável conscientemente. Busca reestabelecer um equilíbrio quebrado pelo conflito psíquico entre o desejo inconsciente e a repressão desse desejo. O sintoma é uma solução de compromisso e também a própria satisfação pulsional do conflito psíquico, é sofrimento e satisfação. E por causa desse caráter de satisfação pulsional muitos paciente optam inconscientemente por manter seus sintomas. E é essa relação individual do paciente com seu desejo que pode afirmar ou negar a eficácia do tratamento analítico e o grau dessa eficácia.

\section{b) Corpo:}

O corpo pode ser entendido de variadas formas. Ele pode ser biológico, o corpo anatômico. Ele pode ser social, em interação com outros corpos. Há o corpo estético, artístico. Há o corpo antropológico, marcado pelo ideal de corpo de uma dada cultura.

O corpo da psicanálise não é o corpo da biologia, da anatomia, da medicina. O corpo da psicanálise é o corpo da significação, dos sentidos inconscientes, o corpo atravessado pela linguagem. 
É o corpo do desejo. E o adoecer do corpo se insere nisso, não é um adoecer da ordem médica, mas da própria significação. O corpo na psicanálise é um corpo sintoma.

Em Freud, trata-se do corpo erógeno, dos buracos, dos intercâmbios com o mundo, do que entra e do que sai. A sede das pulsões - oral, anal, escópica, invocante - e dos objetos que lhes correspondem - o seio, as fezes, o olhar, a voz. Em psicanálise, o corpo também é o corpo da fantasia, do imaginário, do ideal de corpo pedido pela cultura.

Também temos, na visão psicanalítica, o corpo narcísico, da auto-satisfação, que unifica as diversas satisfações corpóreas numa imagem corporal reconhecível pelo sujeito como sendo ele mesmo. Por esse motivo, o "eu", aquilo que reconhecemos como uma unidade que significa nós mesmo, esse "eu" é corporal. Pontua Assoun (1995) "o eu e o corpo estão estruturados, segundo a lógica das superfícies", ou seja, "não que o eu é análogo ao corpo, mas que a emergência da subjetividade se faz segundo esta lógica corporal da projeção" (p. 188).

A totalização do "eu" numa imagem corporal é descrita por Birman (1999):

(...) a resultante dessa operação é a construção do eu e do corpo unificado que são as duas faces da mesma realidade, pois para o sujeito a experiência de ter e ser eu implica para ele habitar um corpo unificado. A condição de unificado remete à noção de ser um, uno, eu, matéria, corpo que se inscreva no espaço e no mundo (p. $35)$.

O conceito de imagem corporal é fundamental para o entendimento psicanalítico dos Transtornos Alimentares. Nessa intercessão entra a Imagem Corporal e os Transtornos da Imagem Corporal, o corpo e suas representações psíquicas, a imagem corporal no psiquismo, possui um sentido único na história do indivíduo, e é constitutiva da narrativa inconsciente que o sujeito faz de si mesmo e que o sustenta.

Esse corpo da psicanálise é o corpo idealizado do bebê por sua mãe na maternagem, sendo esse o lugar onde nasce o sujeito. A construção da identidade do sujeito está inconscientemente relacionada a essas idealizações e à imagem corporal unificada de si. Muitas vezes nos transtornos alimentares, seja a anorexia, seja a obesidade mórbida, há uma distorção na percepção de sua imagem corporal por parte do sujeito, ou seja, o sujeito vê não o que o espelho lhe mostra, num sentido físico, mas sim o que seu próprio psiquismo deseja.

O entendimento da obesidade pela psicanálise passa por essa distinção entre o corpo biológico da medicina e o corpo de sentidos, desejos e idealizações da psicanálise.

\section{c) Pulsão:}

Pulsão é um conceito estruturante em psicanálise, bem como complexo e muito amplo. O conceito de pulsão na psicanálise relaciona o corpo biológico e o psiquismo, Freud descreve a pulsão como sendo o limiar entre o somático e o psíquico. A pulsão é assim identificada, grosso modo, como 
sendo o representante psíquico dos estímulos corporais orgânicos que chegam à mente. Tornando dessa forma somático e psíquico indissociáveis. A pulsão é,

(...) o representante psíquico das excitações que se originam no interior do corpo e chegam ao aparelho psíquico como uma exigência de trabalho que é imposta ao psíquico em consequência de sua ligação com o corporal. (FREUD, 1915, p. 149)

A pulsão busca incessantemente a satisfação, é o motor do aparelho psíquico, direcionando-se para objetos que possam momentaneamente satisfazê-la. A pulsão nunca cessa, é o desejo que nunca para de desejar, sendo assim sua satisfação total é impossível.

A pulsão não possui objeto fixo, podendo fixar-se nos mais diversos objetos buscando sua satisfação, observando-se que essa satisfação é sempre parcial, o que enseja novos deslocamentos pulsionais.

O entendimento pulsional implica que não se come apenas para se alimentar, para se nutrir, as necessidades fisiológicas estão submetidas ao desejo e à significação inconsciente que o ato de comer tem para um dado indivíduo.

Um dos reguladores da dinâmica pulsional é o princípio do prazer

(...) o curso desses eventos é colocado em movimento por uma tensão desagradável e que toma direção tal, que seu resultado final coincide com uma redução dessa tensão, isto é, com uma evitação do desprazer ou uma produção de prazer. (FREUD, 1920, p. 17)

O que nos coloca novamente no campo da satisfação pulsional. Os dois componentes da pulsão descritos por Freud são o afeto e a idéia. Por causa de sua composição dual, uma pulsão nunca pode tornar-se um objeto da consciência, apenas a sua parte ideativa pode ser conscientemente representada. Por esse motivo, a energia do afeto componente da pulsão precisa no manejo clínico passar por simbolização e ser dispersada em mediações do circuito pulsional, levando assim a uma satisfação parcial da pulsão.

A pulsão se inscreve do aparelho psíquico no primeiro momento de vida do indivíduo, no contato primordial entre a mãe e o bebê. E este momento inicial de inscrição da pulsão no psiquismo é fundamental e determinante para toda a história futura do sujeito e para os futuros caminhos da pulsão nessa subjetivação.

O corpo do sujeito, como já discutido, é um corpo pulsional, um corpo que deseja incessantemente, pontuando-se aqui que esse desejo nunca será satisfeito totalmente, deslocando-se em satisfações parciais.

Em Freud, a pulsão ancora o psiquismo no corpo e é o correlato psíquico das necessidades fisiológicas, que nesta perspectiva nunca são meramente fisiológicas. 
Nesta apresentação sucinta sobre Pulsões na teoria psicanalítica cabe uma menção a segunda tópica freudiana após "Além do princípio do prazer", onde é estabelecida a polarização e contraposição entre pulsão de vida e pulsão de morte.

(...) as pulsões de vida tendem, não apenas a conservar as unidades vitais existentes, como a substituir, a partir destas, unidades mais englobantes e as pulsões de morte tendem para a destruição das unidades vitais, para a igualização radical das tensões e para o retorno ao estado inorgânico que se supõe ser o estado de repouso absoluto. (LAPLANCHE; PONTALIS, 1983, p. 537).

Essa tendência a equilibrar radicalmente as tensões psíquicas representada na Pulsão de Morte é especificamente importante no entendimento da obesidade mórbida, onde a busca da satisfação pulsional do princípio do prazer não é suficiente, sendo a Pulsão de Morte uma busca pela satisfação pulsional total.

\section{Articulação de conceitos}

Numa perspectiva psicodinâmica como a psicanálise a obesidade possui relação com características psicológicas internas tais como o controle, a percepção de si, a ansiedade e o desenvolvimento emocional do indivíduo.

Comer aqui não é um ato orgânico, não é um ato biológico.

O corpo da medicina dá lugar a um corpo mapeado por zonas erógenas, um corpo de fantasias, um corpo pulsional. A necessidade fisiológica está para o corpo biológico assim como a pulsão está para o desejo.

O desejo surge do afastamento entre a necessidade e a exigência. Não é mais um objeto real que satisfaz, mas um objeto-fantasma... O corpo fantasmático é o corporepresentação, e não um corpo anatomofisiológico (VARELA, 2006).

Para Varela (2006), o obeso expressa no corpo o que não consegue ou que foi interditado de expressar na linguagem, nos seus sonhos ou nas suas fantasias, é uma forma de expressar seu desejo sem reconhecê-lo como seu. O obeso sente, mas, não conseguindo significar a sensação como linguagem falada, ele significa no corpo. Assim, nessa autora, o obeso sofre por uma falha no processo de simbolização. Essa falha impede um deslocamento simbólico, que possibilitaria o recurso da fantasia.

Para a psicanálise a obesidade se insere numa rede de significantes inconscientes e responde a demandas inconscientes do sujeito. Seu manejo clínico busca ressignificar o sentido inconsciente que o sujeito atribui a si e a seus sintomas, sempre levando em consideração que os sintomas - no caso 
específico transtornos alimentares ou transtornos da imagem corporal - trazem sempre um prazer e uma satisfação que os torna difíceis de serem abdicados pelo paciente.

\section{Modelo Cognitivo-Comportamental}

O segundo modelo psicológico hegemônico de intervenção clínica na obesidade é o Cognitivo-Comportamental. A Terapia Cognitivo-Comportamental é uma derivação do Behaviorismo e dos modelos Cognitvos de Psicologia da Aprendizagem e diverge da Psicanálise e das outras terapias psicodinâmicas/mentalistas. No modelo psicanalítico a obesidade é entendida como uma manifestação somática possível de conflitos psicológicos adjacentes, que transcorrem numa psicodinâmica interna. Toda essa problemática é irrelevante para a clínica cognitivo-comportamental, o modelo cognitivocomportamental trata tão somente de comportamentos-alvo inadequados - patológicos ou desadaptativos - e de problemas de aprendizagem subjacentes que sustentam esses comportamentos. É uma intervenção baseada "no aqui e no agora", com objetivos claros definidos desde o início.

O mentalismo, ao fornecer uma aparente explicação alternativa, mantinha a atenção afastada dos acontecimentos externos antecedentes que poderiam explicar o comportamento. O behaviorismo metodológico fez exatamente o contrário: com haver-se exclusivamente com os acontecimentos externos antecedentes, desviou a atenção da auto-observação e do autoconhecimento. $\mathrm{O}$ behaviorismo radical restabelece um certo tipo de equilíbrio. Não insiste na verdade por consenso e pode, por isso, considerar os acontecimentos ocorridos no mundo privado dentro da pele. Não considera tais acontecimentos inobserváveis e não os descarta como subjetivos. Simplesmente questiona a natureza do objeto observado e a fidedignidade das observações. (Skinner, 1974, p. 19)

Nessa perspectiva teórica, a obesidade, e a obesidade infantil em específico, seria decorrência de uma série de comportamentos, hábitos e crenças inadequados, apreendidos no decorrer da vida do indivíduo e passíveis de modelagem, ou seja, modificáveis.

O princípio fundamental do modelo cognitivo-comportamental é que a maneira como os indivíduos percebem e processam cognitivamente a realidade influenciará a maneira como eles se sentem e se comportam. Apresentar-se-ão agora alguns conceitos fundamentais para o entendimento desse modelo.

a) Tríade Cognitiva: Tendência do paciente ter uma visão negativa de si mesmo, do mundo e do futuro. As tríades cognitivas são específicas de cada paciente e devem ser trabalhadas no processo terapêutico.

b) Pensamentos Automáticos: São pensamentos no limiar da consciência, espontâneos e rápidos, e dão uma interpretação imediata da realidade. São pensamentos iniciais sem reflexão crítica que e se 
distinguem do fluxo normal do pensamento reflexivo. Interpretações automáticas distorcidas são fundamentadas por pensamentos disfuncionais mais profundos chamados nesse modelo teórico de Esquemas ou Crenças Nucleares. Esses pensamentos automáticos e sua interpretação podem levar a distorções cognitivas.

c) Distorções Cognitivas: São pensamentos equivocados, que não se sustentam frente à realidade.

Os mais comuns são:

- Castastrofização - Esperar sempre que o pior desfecho possível de uma situação aconteça, sem considerar outras possibilidades;

- Raciocínio Emocional - Considerar que sentimentos são fatos. Crer que algo é verdade apenas porque está "sentindo" que é;

- Polarização - Pensamentos do tipo "ou tudo ou nada". O pensamento transita apenas entre duas categorias extremadas mutuamente excludentes, sem meio termo;

- Abstração Seletiva - O pensamento usa uma espécie de "filtro" e só um ou poucos aspectos de uma situação são destacados. É o típico caso em que o sujeito só vê o que quer e está predisposto a ver, negando o restante da realidade;

- Leitura Mental - Presumir, sem evidência alguma, que sabe o que outrem pensa;

- Rotulação - Infligir um rótulo universalizante e fixo a si mesmo, a outros, ou a uma situação. O sujeito não consegue compreender a transitoriedade e às especificidades das circunstâncias ;

- Minimização ou Maximização - Características positivas em si mesmo, nos outros ou em dadas situações são minimizadas, enquanto características negativas são maximizadas;

- Imperativizar - Compreender a realidade em termos imperativos, "deve ser assim", "tenho que ser assim". O pensamento foca em idealizações em vez de focar em como as coisas são. Altas demandas feitas a si mesmo, aos outros ou ao mundo.

d) Esquemas mentais ou Crenças Nucleares: Esquemas ou crenças nucleares são estruturas cognitivas internas relativamente duradouras que armazenam características genéricas ou prototípicas de estímulos, idéias ou experiências, usadas para organizar novas informações de maneira significativa determinando como os fenômenos são percebidos, experienciados e conceitualizados (KNAPP; BECK, 2008).

A partir do momento que uma crença básica é formada ela pode influenciar a formação de novas crenças relacionadas, incorporando-se na estrutura cognitiva e influenciando o modo do indivíduo catalogar seus conhecimentos do mundo e sua percepção e interpretação destes.

As crenças nucleares começam na infância e se tornam idéias inquestionáveis para o indivíduo, são "verdades absolutas" que modelam o modo de pensar e perceber.

Crenças nucleares são globais, rígidas e universalizantes e influenciam atitudes, regras pessoais e suposições. 
Id on Line Revista Multidisciplinar e de Psicologia

Id on Line Multidisciplinary and Psychology Journal

As pessoas tendem a "ler" o mundo pela lente de suas crenças nucleares construídas ao longo de sua história de vida. Crenças disfuncionais vão levar a novos pensamentos disfuncionais relacionados, culminando em comportamentos desadaptativos para o indivíduo.

As crenças nucleares possuem também um determinado nível de carga emocional, o que dificulta sua racionalização e pode determinar maior ou menor dificuldade no processo de tratamento. Há uma relação entre afeto e cognição, onde o aumento da distorção cognitiva pode reforçar uma distorção emocional ou o inverso.

e) Modo de Ação: Refere-se a todos os comportamentos aprendidos e mantidos pelo indivíduo. $\mathrm{Na}$ proporção da influência do seu sistema de crenças e pensamentos automáticos disfuncionais o paciente passa a tomar uma série de decisões parecidas como resposta, é um modo de ação ou set. Comportamentos disfuncionais mantidos por um sistema de crenças e pensamentos equívocos.

\section{Articulação de Conceitos}

No modelo cognitivo-comportamental conflitos mentais internos são irrelevantes para a compreensão da obesidade. A obesidade adulta e infantil são compreendidas como um conjunto de comportamentos inadequados construídos na história de vida do indivíduo e suportado por um sistema de crenças e pensamentos equivocados. Há nessa perspectiva um problema de aprendizagem, o indivíduo aprendeu no decorrer de sua vida a pensar e a agir de forma incorreta o que determina seus hábitos alimentares e hábitos de saúde como um todo.

Esse modelo é uma das mais eficientes abordagens psicológicas no tratamento da obesidade, pois com objetivos claros e duração determinada permite a modelagem de comportamentos que propiciam e reforçam a obesidade.

\section{Obesidade e Desenvolvimento}

O conceito de desenvolvimento refere-se às mudanças que ocorrem ao longo do ciclo de vida de um indivíduo. Teorias sobre o desenvolvimento contribuem para a compreensão de fatores que determinam mudanças de comportamento ao longo do tempo. Há várias e diversas concepções sobre o desenvolvimento humano, cada uma delas com ênfase em aspectos distintos que vão desde uma 
perspectiva mais biologizante e maturacional até os aspectos sócio-históricos do desenvolvimento humano.

Para um melhor entendimento da obesidade, em específico da obesidade infantil, todos esses fatores são importantes. A maturação biológica e o desenvolvimento motor, por exemplo, possuem relação com a obesidade. O desenvolvimento cognitivo, social e emocional também são influenciados pela obesidade, crianças obesas tendem a apresentar retraimento social, baixa auto-estima, comportamentos mais infantilizados e regredidos, além de grande dependência materna (CAMPOS, 1993).

\section{Obesidade e Desenvolvimento Motor}

Estudos no campo da Educação Física têm mostrado que crianças obesas apresentam significativo atraso no desenvolvimento motor (BERLEZE; HAEFFNER; VALENTINI, 2007). O início da escolarização formal é um marco importante no desenvolvimento físico e social da criança, atividades físicas em grupos passam a ser uma constante. Um estilo de vida urbano e sedentário associado à obesidade contribui para que crianças obesas tenham um desempenho acentuadamente mais baixo quando participam de jogos ou exercícios.

No desenvolvimento motor da criança há uma relação entre fatores maturacionais biológicos e fatores ambientais que sirvam de estímulo para esse desenvolvimento. $\mathrm{O}$ organismo humano segue uma lógica biológica de desenvolvimento, um calendário maturativo, ao mesmo tempo em que o ambiente, a alimentação, as atividades lúdicas, a socialização e os estímulos físicos interferem nesse calendário.

$\mathrm{O}$ atraso motor de crianças obesas parece estar relacionado à dificuldade física em responder aos estímulos na realização da atividade proposta, além de uma possível vergonha da exposição de sua aparência corporal. Evitar essa exposição faz com que a criança obesa escolha atividades de baixo gasto calórico. Crianças obesas são muitas vezes excluídas por seus pares em atividades desportivas e em grupos, o que diminui ainda mais o espectro de estímulos motores aos quais elas estão expostas, interferindo no seu desenvolvimento. É frequente que ocorra por parte de crianças obesas ou com sobrepeso a troca de atividades físicas ao ar livre por atividades sendentárias em casa, limitando assim o desenvolvimento de capacidades motoras latentes que precisam ser estimuladas nessa etapa da vida do indivíduo.

Crianças obesas comumente apresentam hipoatividade física, maior dificuldade que a média do seu grupo para realizar certo nível de exercício, menor eficiência mecânica, maior demanda energética para um mesmo esforço, e processos metabólicos e hormonais diferenciados dos das crianças não-obesas. 
Poeta et al (2010) dizem que crianças obesas possuem diferença significante, com valores inferiores, para o desenvolvimento motor geral, a motricidade global, o senso de equilíbrio e a percepção do esquema corporal. Também é indicada uma não correspondência entre idade cronológica e idade motora geral em crianças obesas, caracterizando atraso de desenvolvimento. A obesidade infantil e o desenvolvimento motor também podem relacionar-se a problemas ortopédicos e de mobilidade.

Do ponto de vista do desenvolvimento psicológico e social das crianças obesas o excesso de peso e um consequente atraso do desenvolvimento motor ramificam-se muitas também em problemas de socialização e dificuldade na sensação de pertencimento a grupos. Problemas emocionais associados também são comuns, tais como dependência, insegurança e ansiedade. A depender da intensidade desses fatores, a criança pode evoluir para um quadro de sofrimento psicológico crônico.

Programas de educação física na escola que estejam atentos a essa problemática podem minimizar as dificuldades das crianças em situação de sobrepeso ou obesidade, ajudando na mudança para um estilo de vida mais saudável e que permita estímulos motores adequados à faixa etária da criança. Um ambiente rico de estímulos em casa também é fundamental para propiciar o adequado desenvolvimento motor, social e emocional da criança.

\section{Psicossociologia: Fatores Ambientais e Nutricionais}

No início do século XX surge o que hoje conhecemos como psicossociologia. A psicossociologia está no limite da psicologia e da sociologia. Ela tem como intuito analisar grupos, comunidades, indivíduos e qualquer outro tipo de organização social nas suas mais variadas situações cotidianas para, através dessa abordagem, considerar o psiquismo, a subjetividade dos mesmos.

Dentro do presente capítulo, a psicossociologia será direcionada à análise dos fatores externos (ambientais, sociais, culturais e alimentares) que contribuem ou que causam a obesidade. Buscaremos apresentar, com um olhar crítico, alguns dos principais fatores que contribuem para a obesidade dentro de ambientes que, hoje em dia, são considerados obesogênicos.

Segundo Souza e Oliveira:

\footnotetext{
Sabe-se que a ocorrência da obesidade nos indivíduos é reflexo da interação entre fatores ambientais com uma certa predisposição genética. Mas, como há poucas evidências de que algumas populações são mais suscetíveis à obesidade por motivos genéticos, reforça-se a teoria de que os fatores alimentares e o estilo de vida seriam os responsáveis pela diferença na prevalência da obesidade em diferentes grupos populacionais (FRANCISCHI et al., 2000; CRAWFORD, BALL, 2002; LIMA et al., 2004; JEFFERY et al., 2006, p. 17).
} 
Os ambientes obesogênicos são um dos maiores desafios para o controle do sobrepeso.

\section{Hábitos Alimentares}

A alimentação é um dos fatores externos mais delicados no que se refere à obesidade. Os hábitos alimentares, já que fazem parte da cultura e da história de um povo, refletem muito na condição de determinado grupo. Inicialmente, o hábito alimentar de cada cultura foi construído de acordo com a disponibilidade local de alimentos. Posteriormente, os indivíduos de um determinado grupo começaram a se relacionar com indivíduos de outras comunidades e, a partir de então, começaram a realizar trocas de alimentos, aumentando, assim, as possibilidades alimentares.

Os alimentos também mantêm relação com a religião, política, economia, sociedade, cultura, clima, psicologia, tecnologia, dentre outros tantos fatores que se ligam direta ou indiretamente ao indivíduo ou a um determinado grupo. Essa relação condiciona a complexidade na alimentação. Não podemos excluir o fato de que comer também é algo que proporciona prazer, tanto por ser algo que reúne amigos e família quanto por ser um ritual onde o indivíduo se satisfaz, onde ele escolhe o que prefere. Entretanto, é sabido que esses costumes vêm mudando e que comer tem se tornado um hábito solitário e cada vez menos saudável.

Segundo Souza e Oliveira:

É necessário conhecer as questões históricas, antropológicas e sociológicas dos novos hábitos alimentares, decorrentes do triunfo dos fast-food, com tendência a transformar o comer em ato solitário, não mais um momento de convívio em família e um ato de prazer, mas apenas um ritual mecânico (SOUZA e OLIVEIRA, 2008, p. 163).

Com o boom econômico da década de 1970, alimentar-se fora de casa se tornou algo que faz parte da rotina dos indivíduos. Essa mudança causou uma grande transformação na estrutura do consumo alimentar, pois comer fora é uma tendência que cresce junto com a obesidade. E, a cada dia, isso se torna algo ainda mais frequente, já que o número de restaurantes, redes de lanchonetes e redes de fast food só aumentam.

Pode-se observar que o comportamento alimentar é bastante complexo, pois apresenta determinantes internos e externos. A comensalidade contemporânea vem acompanhada da falta de tempo (para que seja possível preparar o alimento em casa de forma mais saudável), do grande número de produtos que agregam comodidade e praticidade, da má alimentação proporcionada às crianças nas refeições escolares, pela variedade de itens alimentares, pelo número indeterminado de estabelecimentos que proporcionam os alimentos, pelos atrativos anúncios publicitários de redes de alimentos, a crescente individualização do momento destinado às refeições diárias, dentre outros grandes motivos. Segundo Reichembach a "escassez de tempo remete o indivíduo à tarefa de decidir 
o que ingerir em um cenário da modernidade pós-industrial, onde várias matrizes poderiam orientar suas escolhas, como o hedonismo ou a disciplina" (REICHEMBACH, 2004, p. 53).

Os padrões nutricionais mudaram e a obesidade está cada vez mais frequente, não somente pela quantidade de alimentos ingerida diariamente, mas também pela composição e pela qualidade da dieta. Contudo, juntamente à dieta o indivíduo deve combinar exercícios físicos.

\section{Exercícios Físicos e Sedentarismo}

Entende-se que todo ser humano, independente de idade, sexo, classe social ou qualquer outro fator cultural, ambiental ou biológico, necessita realizar atividades físicas. Atividade física é qualquer movimento corporal que resulta em gasto energético maior que os níveis de repouso. Existe um grande leque de exercícios que podem ser realizados para que haja esse gasto energético diariamente: jogos, lutas, deslocamentos, exercícios físicos, danças, esportes, além de movimentos da vida diária, como ir para o trabalho a pé, subir escadas, realizar atividades de lazer e recreações. Contudo, é sabido que os altos índices de sedentarismo preocupam bastante, já que a falta de exercícios físicos que resulta num estado onde os movimentos corporais são mínimos, fazendo com que o gasto energético seja muito pouco, contribui bastante para o desenvolvimento da obesidade.

É notável a diminuição de atividades físicas realizadas pelo indivíduo durante o dia a dia. O uso descontrolado de automobilísticos, a falta de vontade de realizar atividades corriqueiras como subir escadas e caminhar até a escola, por exemplo, faz com que ele seja menos ativo. No caso das pessoas que se encontram obesas deve-se observar que elas têm uma tendência ainda maior ao sedentarismo, já que ela passa a encontrar dificuldades para realizar pequenos movimentos, como dar um passo ou levantar do sofá, por exemplo. Pois, muitos desses movimentos podem lhe causar dores, aumento do estresse e fadiga.

A comercialização da cultura também interfere no sedentarismo. É sabido que o lazer é algo de grande valia, uma vez que ela integra o indivíduo ao meio social e cultural. Uma das características do lazer é a liberdade de escolha que a pessoa tem. É possível buscar o prazer, a fuga do tédio de acordo com a sua personalidade, já que essa é uma escolha íntima. No entanto, a sociedade atual tem direcionado os indivíduos a buscarem as mesmas coisas, já que a cultura tem sido transformada em mercadoria, tem sido massificada e a mídia é a principal responsável por essa venda de ideias.

Segundo Rossi e Silveira:

As escolhas de consumo não podem ser entendidas sem se considerar o contexto cultural no qual elas são feitas. Mais do que isso, a cultura cumpre o papel de lentes, através das quais as pessoas vêem os produtos; portanto, o comportamento de compra é extremamente influenciado pela cultura (ROSSI; SILVEIRA, 2002, p. 22). 
Na contemporaneidade a mídia interfere tanto na construção quanto na desconstrução dos procedimentos alimentares, pois o indivíduo acaba adotando algo que não o constitui, ele adota aquilo que o insira num determinado meio.

\section{A Influência da Mídia e dos Equipamentos Multimídia no Sobrepeso}

É sabido que a cada dia os aparelhos eletrônicos se tornam cada vez mais atrativos e interativos, isso resulta num menor interesse por parte da pessoa em sair de casa. Computadores, tablets, sistemas de jogos, televisão, smartphones são aparelhos muito comuns em qualquer residência hoje em dia. O fácil acesso a esses meios oferece às crianças a oportunidade de conhecer "o mundo" sem que seja necessário se locomover e o tempo em excesso que o indivíduo passa utilizando esses meios o torna altamente sedentário.

Segundo Almeida (2002), as crianças passam em média 5 horas diárias assistindo televisão. Esse hábito, segundo Teixeira (2008), também revelou que as crianças passam a consumir uma grande quantidade de alimentos que possuem gorduras (biscoitos, salgadinhos de pacote, guloseimas, chocolates, etc.). Ou seja, por passarem muito tempo entretidas diante da televisão, as crianças preferem se alimentar com praticidade, por isso a escolha por junk food, mesmo que esses possuam uma grande densidade energética.

O número incontrolável de campanhas publicitárias que apresentam os mais variados tipos de alimentos também é um dos responsáveis pela obesidade. Segundo Serra e Santos:

\footnotetext{
Vivemos em um "fast-food cultural", onde as informações são veiculadas sob a urgência do tempo, ou seja, uma comunicação instantânea, onde os telespectadores se tornam "marionetes" dos meios de comunicação que criam valores míticos como liberdade, autonomia, felicidade e bem-estar, e prescrevem, simultaneamente, comportamentos adequados ao alcance de tais fins (SERRA; SANTOS, 2003, p. 691).
}

É notável que as crianças acabam se influenciando ainda mais diante dos comerciais cheios de animações, belas imagens, cores e saborosos alimentos e acabam consumindo-os em grande escala. Esses fatores tornam evidente que muito tempo gasto diante da televisão está relacionado aos maus hábitos alimentares e ao sedentarismo.

\section{Possibilidades de Intervenção Psicológica na Obesidade Infantil}

\section{Educação em Saúde e Prevenção da Obesidade}


A prevalência da obesidade exógena, aquela determinada fundamentalmente por fatores externos, faz com que a mais eficiente intervenção do psicólogo não seja clínica e sim sobre esses determinantes externos anteriormente elencados.

Tal papel comumente é exercido na escola pelo psicólogo escolar, bem como por pedagogos e psicopedagogos. As estratégias utilizadas são de modo geral preventivas, que buscam modificar o modo de vida da criança obesa, além de lidar no ambiente escolar ou em grupos sociais com o eventual preconceito, estigma ou discriminação do obeso.

Diante disso o modelo teórico de intervenção amplamente usado para a obesidade infantil em ambiente escolar e/ou em grupos sociais é o da Educação em Saúde. Educação e Saúde significa que o profissional de saúde, no caso específico o psicólogo atuará em prol da promoção da saúde no ambiente escolar e também em outras circunstâncias que necessitem de um trabalho educativo e preventivo. Sendo esse campo um limiar entre a educação e a saúde e sua finalidade é antes prevenir consequências de eventuais problemas de saúde. O conceito ampliado de saúde aqui inclui além da ausência de doença, o bem estar físico, mental e social, como proposto pela Organização Mundial da Saúde.

Fernandes, Rocha e Souza (2005) dizem que a escola sendo um lugar de formação contínua e inclusão, possui importante papel na construção de hábitos e atitudes dos alunos, onde os valores expressos pela instituição são cotidianamente incorporados pelas crianças em suas vivências. Assim, o psicólogo escolar, o pedagogo ou psicopedagogo, e os professores têm papel ativo na construção desses hábitos das crianças. Projetos pedagógicos visando a obesidade infantil podem e devem ser incentivados e implementados com o objetivo de controlar e minimizar os fatores externos que a influenciam.

Especificamente sobre a obesidade infantil, uma importante estratégia educativa e preventiva é a Educação Nutricional. A educação nutricional além de promover conhecimentos nutricionais deve levar em consideração outros fatores determinantes da dieta, como se há ou não ambiente favorável para melhorar a qualidade da dieta. Na escola, os professores podem realizar programas de educação nutricional, promovendo no ambiente escolar e familiar o consumo de alimentos saudáveis. Fazer a criança ter uma relação saudável com o alimento e não sucumbir ao marketing pesado da indústria alimentícia é fundamental, trabalhar a relação afetiva com o alimento, o contato direto com produtos naturais. Na escola a criação de hortas pelas crianças pode ajudar nesse objetivo. Palestras e seminários explicando o processamento dos alimentos e as vantagens de alimentos naturais sobre os industrializados também são eficazes. Considerar a realidade sociocultural dos alunos permite buscar a melhor alimentação possível, tanto na escola quanto em casa, dentro desse contexto.

Outro trabalho passível dentro do ambiente escolar com a orientação do psicólogo escolar é o controle da saciedade. É comum que alguns adultos exijam ou obriguem crianças a comerem toda a 
comida posta, essa prática pode levar a criança a perder o ponto de saciedade. A sensação de saciedade é derivada de estímulos fisiológicos enviados ao cérebro e indica que a refeição foi suficiente, essa sensação deve ser respeitada na criança e trabalhada para que as crianças que perderam esse controle possam retomá-lo.

Outro trabalho educativo importante para a promoção da saúde em crianças obesas é o combate ao sedentarismo. As escolas podem criar programas de educação física preventivos para a obesidade, aliando componentes lúdicos às atividades físicas. Um psicólogo escolar atento também pode utilizar esses grupos de crianças mobilizados para as atividades físicas preventivas como grupos de discussão de preconceitos, estigmas ou discriminação do obeso. Dessa forma, um trabalho de inclusão e pertencimento ao grupo das crianças obesas pode ser eficaz.

Essas intervenções educativas e promotoras da saúde devem ser realizadas em parceria com a família, para que novas práticas alimentares e de atividades físicas ressoem no ambiente doméstico.

Num roteiro para a estratégia de prevenção temos, de forma resumida, os seguintes componentes:

a) Diminuição Calórica:

- Diminuir alimentos ricos em gordura;

- Diminuir o tamanho das porções dos alimentos;

- Aumentar a quantidade de frutas, vegetais e fibras naturais;

- Diminuir refrigerantes;

- Diminuir o hábito de comer assistindo televisão;

- Diminuir a exposição da criança à propaganda de alimentos, marketing e cultura de consumo.

b) Aumentar o Gasto Energético:

- Diminuir o comportamento sedentário;

- Aumento global da atividade física;

- Mudança de estilo de vida;

- Educação física na escola;

- Atividades físicas em grupo após a escola e nos fins de semana;

- Substituir carro e ônibus por caminhadas ou bicicleta;

- Inserir atividades físicas nas atividades familiares 
Id on Line Revista Multidisciplinar e de Psicologia

Id on Line Multidisciplinary and Psychology Journal

Intervenções de Educação em Saúde devem ser realizadas não por um profissional isolado, mas por toda a equipe da escola, de forma integrada. Com a inserção de projetos na prática diária. Para essa integração é necessário que haja um ambiente propício para trocas de vivências entre a equipe psicopedagógica e o restante do corpo de profissionais que compõe a escola. É preciso a compreensão por parte desses profissionais que saúde, educação e desenvolvimento devem estar inter-relacionados.

A educação e promoção da saúde transcendem ações exclusivamente pedagógicas, sendo prioritariamente o desenvolvimento de possibilidades que gerem mudanças pessoais e sociais.

\section{Psicologia Clínica e Obesidade: Possibilidades e Modelos de Intervenção}

A psicologia clínica em crianças obesas basicamente segue duas linhas: a compreensão da psicodinâmica subjacente à obesidade e a modelagem do comportamento e da cognição.

\section{Clínica Psicanalítica da Obesidade}

Hilde Bruch (1986) foi uma psicanalista precursora do entendimento psicodinâmico dos Transtornos Alimentares e/ou dos Transtornos da Imagem Corporal, e seu trabalho busca as motivações e simbologias inconscientes desses transtornos.

A clínica analítica da obesidade busca compreender a relação necessidade/desejo no ato de alimentar. A terapêutica busca desvelar as motivações inconscientes do paciente obeso e compreender a simbologia da obesidade dentro da história de vida daquela criança obesa. A obesidade possui significados simbólicos profundos e inconscientes de acordo com a singularidade de cada paciente.

Apesar da obesidade se inserir singularmente na narrativa inconsciente de cada indivíduo, psicanalistas de diferentes países têm se deparado com fantasias e significações simbólicas bastante similares entre seus pacientes. $\mathrm{O}$ estudo de casos de pacientes obesos permite a teoria psicanalítica formular correlações e modelos explicativos que são utilizados na clínica.

Uma das fantasias inconscientes comum é que a gordura corporal representava um reservatório nutricional e também um abrigo contra o frio, ou seja, alimento e proteção, no que se pode entender como uma internalização da "mãe". É como se o obeso trouxesse dentro si a própria mãe que lhe aquece e alimenta.

Abadi (1971) relata um caso onde essa simbologia estava presente, e dizia ele que havia uma espécie de regressão para dentro do ventre da mãe, onde estar envolto em sua própria gordura significava para o paciente algo próximo ao ambiente intra-uterino. Com o mesmo paciente também ocorria da gordura corporal significar um acolchoado defensivo que atenua os ataques de um ambiente 
hostil e agressivo. Na interpretação analítica desses significados surgiu a noção de dois seres habitando o mesmo corpo: o gordo e o magro. Um Eu e um Não-Eu. O Eu verdadeiro estaria assim protegido pelo envoltório adiposo. O paciente teria então dois esquemas corporais: um que incluiria a camada de gordura que o protege ("o gordo") e outro que seria seu Eu verdadeiro, sem a proteção da gordura, que seria seu esquema corporal verdadeiro, mas ao mesmo tempo percebido como muito fraco e vulnerável.

Essas fantasias que relacionam gordura com força e proteção se repetem na literatura.

Num estudo clínico com meninas obesas realizado no Hospital das Clínicas de Campinas - SP (BATTISTONI, 1996) os significados inconscientes que surgiram indicavam que a obesidade era um mecanismo de defesa para:

- Esconder fraquezas interiores através de uma presença imponente, como compensação para a fragilidade e insegurança que elas sentiam, numa tentativa de afirmação de uma auto-imagem positiva;

- Diferenciar-se no grupo, afirmando uma individualidade e um 'peso' entre as outras meninas;

- Amortecer ataques do mundo externo hostil. A gordura seria uma capa protetora contra as dores do mundo;

- Camuflar uma agressividade profunda sob a imagem de 'fofinha';

- Negar-se a adentrar o mundo adulto com um corpo roliço infantil e fixação oral representada pela voracidade em se alimentar;

- Descarregar tensões no ato de comer;

- Negar perdas e lutos da infância e da adolescência, compensando o sofrimento psíquico decorrente através da incorporação de "objetos bons" simbolizados pela comida;

- Ocultar a emergência da sexualidade, evitando assim a rivalidade inconsciente com a mãe.

Partindo dessas significações da gordura como proteção e segurança, surgem algumas explicações para a dificuldade no tratamento de obesos:

a) Sendo a obesidade uma defesa e uma compensação de um sentimento de fragilidade e inferioridade, ao emagrecer o paciente passa a se sentir frágil, desamparado e inferiorizado;

b) Considerando a obesidade uma defesa contra a emergência da sexualidade, predominantemente na passagem para a adolescência, que busca converter o sujeito em um objeto desinteressante sexualmente, o emagrecimento traz a angústia para o paciente em ter que lidar com sua própria sexualidade; 
c) Se o ato de comer funciona como um alívio para tensões constantes, ao entrar em dieta o sujeito passa a experienciar intensamente essas tensões e um sentimento de angústia;

d) Se o envoltório de gordura é uma forma de mascarar profunda agressividade sob a aparência de 'fofinho' (há também uma identificação comum de obesos com passividade e calmaria), o emagrecimento pode levar o sujeito ao descontrole de seus impulsos agressivos, o que pode causar culpa e angústia.

Ou seja, se a obesidade funciona como um amplo mecanismo de defesa para conflitos internos, ao emagrecer o sujeito precisa confrontar-se com esses conflitos. É importante que o plano terapêutico já preveja o aparecimento desses conflitos inconscientes em decorrência do avanço do tratamento.

Além dessa descrição geral comum no trato analítico de obesos, alguns conflitos específicos podem surgir. É comum que para alguns pacientes a obesidade seja um autocastigo decorrente de um profundo sentimento de culpa inconsciente.

Outra situação específica e também comum é a obesidade por identificação, ocorrendo predominantemente entre mãe e filha, onde a filha identifica-se com a mãe obesa no desejo de ocupar seu lugar.

Na intervenção clínica são comuns racionalizações por parte do paciente para justificar o nãoemagrecimento. Essas racionalizações têm a função de manter os ganhos dos sintomas, uma vez que todo sintoma traz satisfações subjacentes que dificultam muito seu desaparecimento. Inconscientemente os pacientes escolhem o prazer que seus sintomas lhes trazem.

Uma concordância geral no tratamento psicanalítico da obesidade é que quanto mais distante o paciente estiver do seu índice de peso normal maiores os conflitos inconscientes mascarados, e maior o risco no desvelamento desses conflitos, podendo surgir em consequências inúmeros outros sintomas neuróticos, psicossomáticos e até psicóticos caso a psicoterapia não ofereça o manejo adequado destes. Em alguns casos há indicativo para psicoterapia prévia ao emagrecimento, e em outros também é indicado psicoterapia familiar.

\section{Clínica Cognitivo-Comportamental da Obesidade}

A intervenção terapêutica cognitivo-comportamental da obesidade é fundamentada na análise e modificação de comportamentos disfuncionais relacionados ao estilo de vida do paciente. A finalidade é implementar estratégias que auxiliem a perda de peso.

O terapeuta parte dos seguintes pressupostos:

- Maior ou menos ingestão alimentar associada à prática ou não de atividade física alteram o peso corporal. Manejar esses dois fatores altera o peso corporal; 
Id on Line Revista Multidisciplinar e de Psicologia

Id on Line Multidisciplinary and Psychology Journal

- O modo como um indivíduo realiza sua ingestão alimentar e o modo como pratica ou não atividade física são comportamentos aprendidos, e como todo comportamento aprendido, pode ser modificado;

- Para que a modificação do comportamento seja efetiva e duradora é preciso que ocorra uma modificação ambiental que reforce o comportamento desejado.

Há quatro momentos na terapêutica:

1. Avaliação da motivação para a mudança;

2. Avaliação da história e do estado atual da condição a ser tratada;

3. Preparo de uma formulação teórica do problema;

4. Planejamento do programa de tratamento.

O programa de tratamento usa estratégias cognitivo-comportamentais para modificar comportamentos inadequados associados à obesidade. As principais estratégias são:

a) Automonitoramento:

O próprio paciente por meio de registros escritos sobre sua ingestão alimentar diária monitora seu comportamento alimentar. Esses registros escritos servem para auxiliar no planejamento do tratamento permitindo ajustes terapêuticos mais precisos. $\mathrm{O}$ automonitoramento também permite o registro de fatores cognitivos associados através de anotações referentes a pensamentos equivocados sobre $\mathrm{o}$ ato de comer, o peso e o aspecto corporal do paciente.

b) Controle de Estímulos:

Busca modificar situações que eliciem comportamentos disfuncionais, ou seja, modifica situações anteriores ao comportamento que se quer evitar, como por exemplo, comer demais ou não fazer atividade física. Exemplos comuns dessa estratégia:

- Fazer compras de supermercado excluindo alimentos proibidos pela dieta;

- Evitar o uso do controle remoto e do carro para estimular atividade física, deixando o controle remoto e o carro indisponíveis;

- Limitar o acesso a comida durante às refeições;

- Evitar situações associadas ao comer em excesso, tais como comer defronte a TV e em eventos esportivos. 
Id on Line Revista Multidisciplinar e de Psicologia

Id on Line Multidisciplinary and Psychology Journal

c) Resolução de Problemas:

Psicólogo e paciente identificam juntos problemas relacionados ao excesso de peso e buscam possíveis estratégias e soluções para esses problemas. Essas estratégias e soluções são aplicadas pelo paciente em seu cotidiano e sua eficácia é avaliada em sessão. A finalidade é instaurar novos padrões de comportamento benéficos para a perda e manutenção do peso.

d) Reestruturação Cognitiva:

É a modificação do sistema de crenças do indivíduo. O psicoterapeuta identifica e corrige crenças e pensamentos disfuncionais relacionados ao peso e à alimentação. A finalidade é extinguir ou minimizar distorções cognitivas comuns em pacientes obesos.

e) Suporte Social:

A participação da família, amigos e corpo clínico envolvido no tratamento da obesidade é fundamental. Esse suporte social auxilia e motiva a perda de peso. Em alguns casos há indicação de grupos terapêuticos, formados por pacientes que enfrentam problemas similares. Um exemplo é o Comedores Compulsivos Anônimos (CCA).

Outros dois pontos importantes da terapêutica são a quantificação da motivação e a definição de objetivos. A quantificação da motivação distingue entre uma vontade genérica por parte do paciente em perder peso e a real disponibilidade dele em se engajar nas estratégias cognitivo-comportamentais para perda de peso. A definição clara de objetivos e metas colabora para a eficiência do tratamento, prazos a serem cumpridos também.

A terapia cognitivo-comportamental no tratamento da obesidade é limitada e ao mesmo tempo extremamente eficaz. Sua limitação refere-se a lidar apenas com modelagem do comportamento e das crenças, sem adentrar eventuais conflitos psicológicos internos. Mas ao mesmo tempo, seus resultados quantificáveis são bastante favoráveis, com alto número de sucessos e satisfação dos pacientes. Além de ser uma terapia de fácil inserção em equipes multidisciplinares, optimizando o tratamento de médicos e nutricionistas.

\section{Considerações Finais}

A obesidade sendo uma doença crônica de causalidade multifatorial por óbvio não pode ser reduzida aos seus fatores componentes. Suas múltiplas facetas a tornam um fenômeno complexo que 
abarca questões orgânicas (genéticas e metabólicas), questões sociais e culturais, e, o objeto de interesse desse trabalho monográfico, questões psicológicas.

A obesidade não pode ser resumida às suas questões psicológicas, mas estas são fundamentais na composição do quadro total do paciente, visando um cuidado de saúde integral. São as questões psicológicas que perpassam a obesidade, em específico a obesidade infantil, a porta de entrada para a compreensão e a intervenção do psicólogo. Essas questões psicológicas não necessariamente são questões clínicas, ou não exclusivamente clínicas. A psicologia é uma disciplina ampla que permite variadas abordagens de um dado fenômeno. A psicologia tanto pode cuidar do sofrimento psicológico individual decorrente da obesidade infantil como também pode intervir no contexto obesogênico. Além da obesidade propriamente dita e de transtornos alimentares e da imagem corporal associados, diversas comorbidades psicológicas comumente se relacionam no paciente obeso. Ansiedade generalizada, baixa-autoestima, depressão, comportamentos regressivos e infantilizados, entre outros, são sintomas que também devem ser amparados pela intervenção psicológica. Muitas vezes neuroses graves são mascaradas pela compulsão alimentar.

A obesidade é hoje uma pandemia mundial, é um problema severo de saúde pública que cumulativamente cria fatores de risco para outras doenças físicas e mentais.

A obesidade infantil nesse contexto é preocupante. Uma criança é considerada obesa quando possui $20 \%$ a mais do peso ideal para a sua idade. Crianças obesas são grupos de risco para bullying, para diabetes infantil, para lesões ortopédicas e musculares, para distúrbios do sono, entre outros problemas de saúde. Entre 40 a $80 \%$ das crianças obesas possuem chances de serem adultos obesos (OLIVEIRA, 2000), o que é impactante para todo o sistema público de saúde. Intervir na obesidade infantil é propiciar qualidade de vida para a criança, e consequentemente para o futuro adulto, é familiarizá-la com a alimentação saudável e prevenir o sedentarismo. Uma vida ativa e saudável traz consequências benéficas tanto para saúde física quanto para a saúde mental.

Esta revisão bibliográfica buscou resumir e caracterizar o quadro geral das relações entre psicologia e obesidade. Problematiza-se aqui a impossibilidade de uma compreensão psicológica unificadora e uma decorrente intervenção única. Muitos modelos psicológicos são excludentes entre si, possuem concepções de sujeito e concepções psicopatológicas inconciliáveis, o que, por exemplo, faz as intervenções psicanalítica e cognitivo-comportamental serem tão distantes uma da outra. Mas ao mesmo tempo, essas múltiplas perspectivas dentro da psicologia de um mesmo fenômeno trazem algum complementaridade. Alguns sujeitos, no caso específico, algumas crianças são mais suscetíveis a uma abordagem que a outra. E de outro lado, a psicossociologia da obesidade também deve ser considerada, a obesidade entendida não como um fenômeno individual e clínico, mas também um fenômeno social, a implicação da obesidade nos grupos sociais da criança, os eventuais estigmas gerados. Obesidade infantil não é um sinônimo de problemas psicológicos e/ou emocionais, ainda que 
Id on Line Revista Multidisciplinar e de Psicologia

Id on Line Multidisciplinary and Psychology Journal

muitas comorbidades emocionais e psicológicas estejam associadas, então, fora do aspecto clínico insere-se o papel educativo da intervenção psicológica.

A ação conjunta do psicólogo com outros profissionais de saúde numa equipe multidisciplinar é imprescindível para o tratamento integral da obesidade em toda sua multicausalidade.

A intervenção do psicólogo, como já mostrado em capítulos anteriores, deve ocorrer na prevenção, através de ações de educação em saúde e de promoção da saúde, e no tratamento, através de intervenções clínicas, sejam psicanalíticas, sejam cognitiva-comportamentais.

Trabalhos como esse objetivam estimular outros estudos mais específicos sobre o tema e mesmo contribuir na fundamentação de políticas públicas de saúde mais eficazes para a promoção da qualidade de vida da população.

\section{Referências}

ABADI, M. Notas acerca de alguns mecanismos en la psicogenesis de la obesidade. In: LIBERMAN, D. et al. Psicologia del obeso. Buenos Aires: Rodolfo Alonso, 1971

BATTISTONI, M. M. M. Obesidade feminina na adolescência: revisão teórica e casos ilustrativos, visão psicossomática. Tese (Doutorado) - Universidade Estadual de Campinas, Campinas, 1996

BERLEZE, A.; HAEFFNER, L. S. B; VALENTINI, N. C. Desempenho motor de crianças obesas: uma investigação do processo e produto de habilidades motoras fundamentais. Revista Brasileira de Cineantropometria e Desempenho Humano, 9. p. 134-144. 2007

BIRMAN, J. Freud e a interpretação psicanalítica. Rio de Janeiro: Relumé/Dumará. (A constituição da psicanálise, v. 2). 1991

BRASIL. Ministério da Saúde. Obesidade. Cadernos de Atenção Básica; nº12. Série A. Normas e Manuais Técnicos. 108 p. Brasília, 2006.

BRUNC, H. The treatment of eating disorders. Mayo Clin. Proc., v. 51, p. 266-272, 1976

CAMPOS, A. L. R. Aspectos psicológicos da obesidade. Rev. Pediatria Moderna, 29, p. 129-133. 1993

FERNANDES, M. H.; ROCHA, V. M.; SOUZA, D. B. de. A concepção sobre saúde do escolar entre professores do ensino fundamental $\left(1^{\mathrm{a}}\right.$ a $4^{\mathrm{a}}$ séries). Rev. Hist. Cienc. Saúde-Manguinhos, Rio de Janeiro, v. 12, n. 2, 2005. Disponível em: <http://www.scielo.br/scielo.php?script=sci_arttext\&pid=S010459702005000200004\&lng=pt\&nrm=iso>. Acesso em: 05 out. 2014

FRANCISCHI, R. P. P.; PEREIRA, L. O.; FREITAS, C. S.; KLOPFER, M.; SANTOS, R. C.; VIEIRA, P. Obesidade: atualização sobre sua etiologia, morbidade e tratamento. Rev. Nutr., v. 13, n. 1, p. 17-28, 2000.

FREUD, Sigmund. Os instintos e suas vicissitudes. In:__ A história do movimento psicanalítico, artigo sobre a metapsicologia e outros trabalhos. Rio de janeiro: Imago. 1914-1916. p.117-123. (Edição standard brasileira das obras psicológicas completas de Sigmund Freud, 14). 1915 
Id on Line Revista Multidisciplinar e de Psicologia

Id on Line Multidisciplinary and Psychology Journal

Conferências introdutórias sobre psicanálise. In. S. Freud, Edição standard brasileira das obras psicológicas completas de Sigmund Freud (J. Salomão, trad., Vol.16, p. 265-279). Rio de Janeiro: Imago. 1916

Conferência XVII. O sentido dos sintomas. In. S. Freud, Edição standard brasileira das obras psicológicas completas de Sigmund Freud (J. Salomão, trad., Vol.16, p. 265-279). Rio de Janeiro: Imago. (Trabalho original publicado em 1917[1916-17]). 1917

Além do princípio de prazer (J. Salomão, Trad.) Em: Edição Standard Brasileira das Obras Completas de Sigmund Freud. (Vol.XVIII, pp. 13- 179). Rio de Janeiro: Imago Editora. (Originalmente publicado em 1920) 1920.

Inibições, sintomas e ansiedade. In S. Freud, Edição standard brasileira das obras psicológicas completas de Sigmund Freud (J. Salomão, trad., Vol.20, p. 81-171). Rio de Janeiro: Imago. 1926

JUSTUS, Dasy. Por uma psicopatologia da alimentação cotidiana. In: Encontro Sul Americano dos Estados Gerais da Psicanálise, São Paulo, 1999

KNAPP, P.; BECK, A. T. Fundamentos, modelos conceituais, aplicações e pesquisa da terapia cognitiva Rev Bras Psiquiatr. 30, (Supl II):S54-64. 2008

LAMPLACHE, J.; PONTALIS, J. B. Vocabulário de psicanálise. São Paulo: Livraria Martins Fontes Editora Ltda. 1983

MEYER, F.; MELLO, E. D; LUFT V. C. Obesidade infantil: como podemos ser eficazes? J Pediatr.; 80(3):173-82. 2004.

MISSHIMA, F. K. T.; BARBIERI, V. O brincar criativo e a obesidade infantil. Estudos de Psicologia, 14 (3), p. 249-255, setembro-dezembro, 2009

OLIVEIRA, R. G. A. Obesidade na infância e adolescência como fator de risco para doenças cardiovasculares do adulto. In: Simpósio Obesidade e Anemia Carencial na Adolescência, 2000, Salvador. Anais... Salvador: Instituto Danone, 2000. p. 65-75.

ORERA, M. Aspectos genéticos de la obesidade. In: Moreno B, Monereo S, Álvarez J. Obesidad: presente y futuro. Madrid: Biblioteca Aula Médica; p.51-69. 1997.

ORGANIZAÇÃO MUNDIAL DA SAÚDE. Obesidade: prevenindo e controlando a epidemia global: relatório da consultoria da OMS. São Paulo: Editora Roca; 2004.

POETA, L. S.; DUARTE, M. F. S.; GIULIANO, I. C. B.; SILVA, J. C.; SANTOS, A. P. M; ROSA NETO, F. Desenvolvimento motor de crianças obesas. R. bras. Ci e Mov, 18(4); p. 18-25. 2010

QUINET, A. As 4 + 1 condições da análise. Rio de Janeiro:Jorge Zahar. 1991

REICHEMBACH, M. T. A refeição em família: um lugar de encontro entre a história da alimentação e da enfermagem. Cogitare Enfermag., v. 9, nº. 2, p. 53-65, 2004

SKINNER, B. F. Sobre o Behaviorismo. São Paulo: Cultrix, 1974.

ROSSI, C. A. V.; SILVEIRA, T. Pesquisa Sobre Culturas Nacionais: O Inexorável futuro do marketing na globalização. Revista Interdisciplinar de Marketing, v. 1, nº. 2, p. 6-22, 2002.

SERRA, G.M.A.; SANTOS, E.M. Saúde e mídia na construção da obesidade e do corpo perfeito. Ciênc. Saúde Coletiva, v. 8, nº. 3, p. 691, 2003. 
SOUZA, Noa P. P. de; OLIVEIRA, Maria Rita M. de. O ambiente como elemento determinante da obesidade. Disponível em: http://www.redesans.com.br/redesans/wp-content/uploads/2012/10/o-ambientecomo-elemento-paraleitura.pdf. Acesso em: 28/10/2014.

VARELA, Ana Paula. Você tem fome de quê? V 26. Brasília/DF. 2006. Disponível em: <http://pepsic.bvs-sisi.org.br/scielo.php?scrip=sci_arttext\&pid>. Acessado em: 24/09/2014

WANG, Y.; MONTEIRO, C.; POPKIN, B. M. Trends of obesity and underweight in older children and adolescents in the United States, Brazil, China, and Russia. Am J Clin Nutr; 75:971-7; 2002.

\section{Como citar este artigo (Formato ABNT):}

SANTOS, R.A.; MARANHÃO, T.L.G. BATISTA, H.M.T. Obesidade Infantil e Abordagens em Psicologia: Uma Revisão da Literatura. Id on Line Revista Multidisciplinar e de Psicologia, Julho de 2016, vol.,10 n.30, Supl 1. p. 345-375. ISSN 1981-1179.

Recebido: 10/05/2016

Aceito: 18/05/2016 